\title{
VALIDASI METODE PENETAPAN KADAR CYANOCOBALAMIN SECARA SPEKTROFOTOMETRI VISIBEL DOUBLE BEAM
}

\author{
Ricson P. Hutagaol dan Niken \\ F. MIPA Universitas Nusa Bangs a \\ Jl. K. H. Soleh Iskandar Km. 4, Cimanggu, Tanah Sareal - Bogor 16166 \\ email : tufakmipa@yahoo.co.id
}

\author{
ABSTRACT \\ Validation of Determination Method of Cyanocobalamin Content by \\ Visible Double Beam Spectrophotometry
}

\begin{abstract}
Validasion of new modification of or method, must be done before the validity of methods and tools used. A valid method will give accurate results so as to guarantee the quality of drugs. The increasing demand from consumers will need increasing vitamin B12, so need more validation methods of cyanocobalamin in the tablet dosage. Analysis of the studied parameter of linearity, accuracy, precision, robustness, specificity, and ranges. Analysis of cyanocobalamin is using a strong base anionic exchange resin for separation techniques in order to obtain pure cyanocobalamin, pure cyanocobalamin obtained after measuring through visible double beam spectrophotometry. The results of this validation of all parameters meet the requirements and acceptance criteria. Linearity parameter obtained resultes of the correlation coefficient $(r)=0,999$ (minimum 0,98). Accuracy parameter of the results abtained between 98,12\% - 99,44\% (requirements between 98\% - 102\%). Precision parameter (repeatability method) obtained relative standard deviation (RSD) between 0,25\% - 0,38\% (requirements is less than 2\%). Intermediate precision parameters between SBR obtained 0,00\% (requirements is less than 2\%). Robustness parameters obtained 98,24\% recovery and RSD was 0,00\% (requirements is between $98 \%-102 \%)$ recovery and RSD less than 2\% (mets the requirements). Specificity parameters obtained that the sample matrix did not affect the results of the analysis, so it could be concluded that the validation of method determination of cyanocobalamin measure was valid.
\end{abstract}

Key words : Method validation, cyanocobalamin, resin, spectrophotometry.

\begin{abstract}
ABSTRAK
Menurut Harmita (2004), metode yang baru atau mengalami modifikasi, sebelum digunakan untuk penetapan rutin harus dilakukan validasi metode terlebih dahulu agar dapat diketahui keabsahan metode dan alat yang digunakan. Metode yang valid akan memberikan hasil yang akurat sehingga dapat menjamin mutu obat. Semakin meningkatnya permintaan dari konsumen akan kebutuhan vitamin B12 (cyanocobalamin), maka perlu dilakukan validasi metode terhadap kadar cyanocobalamin dalam sediaan tablet. Parameter analisis yang diteliti yaitu linieritas, akurasi, presisi, ketegaran, spesifisitas, dan rentang. Analisis cyanocobalamin ini menggunakan resin penukar anionik basa kuat untuk teknik pemisahan agar didapatkan cyanocobalamin murni, setelah didapatkan cyanocobalamin murni maka kadarnya dapat diukur secara spektrofotometri visible double beam. Hasil penelitian dari seluruh parameter validasi ini memenuhi persyaratan dan sesuai kriteria penerimaan. Parameter linieritas didapatkan hasil koefisien korelasi $(r)=0,999$ sesuai persyaratan yaitu minimum 0,98 . Parameter akurasi didapatkan hasil \% recovery diantara $98,12 \%$ - 99,44\% sesuai persyaratan yaitu diantara $98 \%$ 102\%. Parameter presisi (kedapatulangan metode) didapatkan hasil simpangan baku relatif (SBR) diantara $0,25 \%$ - $0,38 \%$ sesuai persyaratan yaitu lebih kecil dari $2 \%$. Parameter presisi antara didapatkan SBR $0,00 \%$ sesuai persyaratan yaitu lebih kecil dari $2 \%$. Parameter ketegaran didapatkan hasil \% recovery $98,24 \%$ dan SBR $0,00 \%$ sesuai persyaratan yaitu \% recovery diantara 98\% - 102\% serta SBR lebih kecil dari 2\% dengan demikian parameter rentang juga memenuhi persyaratan. Parameter spesifisitas diperoleh hasil bahwa matriks sampel tidak mempengaruhi hasil analisis, sehingga dapat disimpulkan bahwa validasi metode penetapan kadar cyanocobalamin adalah valid.
\end{abstract}

Kata kunci : Validasi metode, cyanocobalamin, resin, spektrofotometri. 


\section{PENDAHULUAN}

Validasi metode adalah suatu tindakan penilaian terhadap parameter tertentu, berdasarkan percobaan laboratorium untuk membuktikan bahwa parameter tersebut memiliki persyaratan untuk penggunaannya. Validasi bertujuan untuk menjamin prosedur yang aman dan menekan sekecil mungkin risiko penyimpangan yang mungkin timbul. Hasil validasi metode dapat digunakan sebagai bahan acuan untuk menentukan suatu metode dapat digunakan untuk pemeriksaan rutin atau tidak (Harmita, 2004).

Cyanocobalamin disebut juga vitamin B12 merupakan senyawa berbentuk kristal, berwarna merah, dan secara kimia merupakan vitamin yang paling kompleks (Departemen Kesehatan Republik Indonesia, 1995). Vitamin B12 merupakan salah satu vitamin yang penting bagi tubuh serta semakin meningkatnya permintaan konsumen akan vitamin B12 di pasaran saat ini, maka dilakukan penelitian mengenai validasi metode terhadap kadar cyanocobalamin dalam sediaan tablet secara spektrofotometri visible double beam, karena metode yang valid akan memberikan hasil analisis yang akurat sehingga dapat menjamin mutu obat tersebut.

Resin penukar anionik basa kuat yang mempunyai gugus $-\mathrm{CH}_{2} \mathrm{~N}\left(\mathrm{CH}_{3}\right)_{3} \mathrm{Cl}^{-}$ mampu memisahkan zat warna serta matriks tablet yang ada pada sediaan tablet yang mengandung cyanocobalamin sehingga akan didapatkan cyanocobalamin murni yang berwarna, oleh karena itu kadar cyanocobalamin bisa ditentukan menggunakan spektrofotometer visibel double beam (Nalco Chemical Company, 2006). Berdasarkan sifat cyanocobalamin yang tidak stabil dengan udara dan cahaya maka penentuan kadar baku cyanocobalamin dilakukan menggunakan harga ekstingsi spesifik (E ${ }^{1 \%}{ }_{1 \mathrm{~cm}}$ ) yang ditentukan pada panjang gelombang maksimum $361 \mathrm{~nm}$. Menurut european pharmacopoeia harga E ${ }^{1 \%}{ }_{1 \mathrm{~cm}}$ untuk cyanocobalamin $=207$, dari harga $\mathrm{E}^{1 \%} 1 \mathrm{~cm}$ ini akan didapatkan nilai absorbansi spesifik untuk cyanocobalamin yang besarnya sesuai dengan konsentrasi larutan yang dianalisis sehingga bisa didapatkan kadar standar baku cyanocobalamin. Selain itu cyanocobalamin mempunyai dua panjang gelombang maksimum yaitu pada $361 \mathrm{~nm}$ dan $550 \mathrm{~nm}$. Panjang gelombang $361 \mathrm{~nm}$ merupakan panjang gelombang mutlak untuk menentukan kadar standar baku cyanocobalamin sedangkan panjang gelombang maksimum untuk sampel bisa menggunakan panjang gelombang $361 \mathrm{~nm}$ atau $550 \mathrm{~nm}$ tergantung dari sifat obat yang dianalisis. Cyanocobalamin yang digunakan untuk standar baku dan sampel sama yaitu berasal dari satu bahan baku (The Committee On JP, 2006).

\section{METODE PENELITIAN}

\section{Bahan dan Alat}

Bahan - bahan yang digunakan dalam uji validasi metode analisis ini adalah cyanocobalamin buatan Sanovi Aventis, asam klorida p.a buatan Merck, Dowex 1-x4 type 100-200 mesh buatan Muromachi Technos, asam asetat (glacial) $100 \%$ p.a buatan Merck, akuades, dan placebo sediaan tablet cyanocobalamin. Peralatan yang digunakan dalam uji validasi metode analisis ini adalah pipet volumetrik (ukuran $2 \mathrm{ml}, 3 \mathrm{ml}, 4 \mathrm{ml}, 5 \mathrm{ml}$, $6 \mathrm{ml}, 10 \mathrm{ml}$, dan $30 \mathrm{ml}$ ), neraca analitik merek Sartorius, labu ukur cokelat (ukuran $50 \mathrm{ml}$ dan $100 \mathrm{ml}$ ), stirrer, piala gelas 300 $\mathrm{ml}$, pipet tetes, bulp, kuvet $10 \mathrm{~mm}$, lemari pendingin, labu semprot, tisu, shaker, centrifuge merek Hettich Mikro $22 \mathrm{R}$, tabung centrifuge, kolom kromatografi berbentuk buret merek Iwata, corong, tabung reaksi $100 \mathrm{ml}$, alu voil, spatula, statip buret, dan spektrofotometer UV-VIS model U2001 merek Hitachi.

\section{Metode Penelitian}

1. Penyiapan Matriks Sampel

2. Penyiapan Kolom Kromatografi

a. Kolom kromatografi : resin penukar anionik basa kuat (Dowex 1-x4, Cl type, $100-200$ mesh. 
b. Penyiapan kolom : setelah resin Dowex dicuci denga cara dekantasi, dengan menggunakan akuades, Dowex dimasukkan ke dalam kolom kaca hingga tinggi kira - kira $7 \mathrm{~cm}$, dilewatkan $6 \times 25$ $\mathrm{ml}$ asam asetat $6 \mathrm{~N}$ melalui kolom lalu dibilas dengan air hingga netral. Kolom diatur hingga $5 \mathrm{~cm}$ sebelum digunakan.

\section{Penyiapan Larutan Standar}

Cyanocobalamin yang telah dikeringkan selama \pm 2 jam pada suhu 105 ${ }^{\circ} \mathrm{C}$ ditimbang $\pm 50 \mathrm{mg}$, dimasukkan ke dalam labu ukur cokelat $50 \mathrm{ml}$, dilarutkan dan diencerkan dengan akuades hingga tanda batas, kemudiaan dikocok hingga homogen. Larutan standar ini adalah larutan standar induk yang digunakan untuk larutan standar baku dan larutan standar sampel cyanocobalamin. Penyiapan larutan standar baku cyanocobalamin yaitu dengan cara larutan standar induk dipipet $4 \mathrm{ml}$ dimasukkan ke dalam labu ukur cokelat $100 \mathrm{ml}$, dilarutkan dan diencerkan dengan akuades hingga tanda batas, kemudian dikocok hingga homogen dan diukur pada $\lambda$ maksimum $361 \mathrm{~nm}$ dengan spektrofotometer UV VIS, dan digunakan air sebagai blanko. Penyiapan larutan standar sampel cyanocobalamin yaitu dengan cara larutan standar induk dipipet $10 \mathrm{ml}$, dimasukkan ke dalam labu ukur cokelat $100 \mathrm{ml}$, dilarutkan dan diencerkan dengan $\mathrm{HCl} 0,1$ $\mathrm{N}$ hingga tanda batas, kemudian dikocok hingga homogen. Larutan tersebut dipipet tepat $60 \mathrm{ml}$, dilewatkan melalui kolom yang dikemas dengan resin penukar ion bersifat basa kuat, dibawah kolom ditempatkan labu ukur $100 \mathrm{ml}$ berwarna cokelat sebagai penampung. Setelah itu kolom dibilas tiga kali setiap kali dengan $10 \mathrm{ml} \mathrm{HCl} 0,1 \mathrm{~N}$ digabungkan bilasan dan ditambahkan $\mathrm{HCl} 0,1 \mathrm{~N}$ hingga $100 \mathrm{ml}$ kemudian dikocok hingga homogen dan diukur pada $\lambda$ maksimum $550 \mathrm{~nm}$ dengan spektrofotometer UV - VIS dan digunakan $\mathrm{HCl} 0,1 \mathrm{~N}$ sebagai blanko.

\section{Penyiapan Larutan Sampel}

$\begin{array}{lll}\text { a. Parameter Akurasi, } & \text { Presisi } \\ \text { (Kedapatulangan Metode), } & \text { Presisi } \\ \text { Antara, dan Rentang } & \end{array}$

Lima belas buah tabung centrifuge ukuran $50 \mathrm{ml}$ disiapkan dan diberi identitas. Matriks tablet masing-masing ditimbang \pm 7,59 gram (setara dengan 20 tablet) lalu dimasukkan ke dalam setiap tabung centrifuge beserta larutan stock untuk masing-masing konsentrasi secara kuantitatif ke dalam setiap tabung centrifuge sesuai dengan ketentuan pada Tabel 1 dan penyiapan larutan stock ini dapat dilihat pada bagian penyiapan larutan stock cyanocobalamin. Setiap tabung centrifuge ditambahkan $30 \mathrm{ml} \mathrm{HCl}$ 0,1 N dikocok selama 10 menit dengan shaker, dipisahkan dengan centrifuge, dan diambil cairan supernatan dimasukkan ke dalam labu ukur cokelat $100 \mathrm{ml}$. Endapan yang berada di dalam centrifuge diekstrak lagi dengan $3 \times 20 \mathrm{ml} \mathrm{HCl} 0,1 \mathrm{~N}$ dan cairan supernatan kembali dimasukkan ke dalam labu ukur cokelat $100 \mathrm{ml}$ lalu ditambahkan $\mathrm{HCl}$ 0,1 N sampai tanda batas $100 \mathrm{ml}$ kemudian dikocok hingga homogen. Cairan supernatan ini disaring lalu dipipet $60 \mathrm{ml}$ dan dimasukkan ke dalam kolom kromatografi. Hasik kromatografi ditampung ke dalam labu ukur cokelat $100 \mathrm{ml}$, kemudian kolom dicuci dengan $10 \mathrm{ml} \mathrm{HCl} 0,1 \mathrm{~N}$ sebanyak 3 kali dan ditampung dalam labu ukur yang sama. Volume labu ukur diimpitkan hingga $100 \mathrm{ml}$ dengan $\mathrm{HCl} 0,1 \mathrm{~N}$, dikocok hingga homogen, diukur pada $\lambda$ maksimum 550 $\mathrm{nm}$ dengan spektrofotometer UV - VIS, dan digunakan $\mathrm{HCl}$ 0,1 $\mathrm{N}$ sebagai blanko. Khusus untuk pengujian presisi antara hanya dilakukan pada konsentrasi $100 \%$ yang diulang sebanyak 3 kali dan dikerjakan oleh orang yang berbeda.

\section{b. Parameter Linieritas}

Lima buah labu ukur cokelat ukuran $100 \mathrm{ml}$ disiapkan, diberi tanda pada labu untuk setiap variasi konsentrasi, dan ditambahkan larutan stock D sesuai dengan konsentrasi yang ada pada Tabel 2. Penyiapan larutan stock D dapat dilihat pada bagian penyiapan larutan stock 
cyanocobalamin. Setiap labu ukur diencerkan dengan $\mathrm{HCl} 0,1 \mathrm{~N}$ hingga tanda batas, kemudian dikocok hingga homogen dan diukur pada $\lambda$ maksimum $550 \mathrm{~nm}$ dengan spektrofotometer UV - VIS dan digunakan $\mathrm{HCl} \quad 0,1 \mathrm{~N}$ sebagai blanko.

Tabel 1. Penambahan Larutan Stock pada Sampel Akurasi dan Pesisi

\begin{tabular}{cccccc}
\hline Identitas & $\begin{array}{c}\text { Variasi } \\
\text { Konsentrasi } \\
\text { (\% terhadap } \\
\text { konsentrasi } \\
\text { sampel b/v) }\end{array}$ & Ulangan & $\begin{array}{c}\text { Larutan } \\
\text { Stock A (ml) }\end{array}$ & $\begin{array}{c}\text { Larutan } \\
\text { Stock B (ml) }\end{array}$ & $\begin{array}{c}\text { Larutan } \\
\text { Stock C (ml) }\end{array}$ \\
\hline SK 1-1 & 80 & 1 & - & 4 & - \\
SK 1-2 & 80 & 2 & - & 4 & - \\
SK 1-3 & 80 & 3 & - & 4 & - \\
SK 2-1 & 90 & 1 & - & - & 10 \\
SK 2-2 & 90 & 2 & - & - & 10 \\
SK 2-3 & 90 & 3 & - & - & 10 \\
SK 3-1 & 100 & 1 & - & 5 & - \\
SK 3-2 & 100 & 2 & - & 5 & - \\
SK 3-3 & 100 & 3 & - & 5 & - \\
SK 4-1 & 110 & 1 & 10 & - & - \\
SK 4-2 & 110 & 2 & 10 & - & - \\
SK 4-3 & 110 & 3 & 10 & - & - \\
SK 5-1 & 120 & 1 & - & 6 & - \\
SK 5-2 & 120 & 2 & - & 6 & - \\
SK 5-3 & 120 & 3 & - & 6 & - \\
\hline
\end{tabular}

Tabel 2. Penambahan Larutan Stock pada Sampel Linieritas

\begin{tabular}{ccc}
\hline Identitas Sampel & $\begin{array}{c}\text { Variasi Konsentrasi } \\
\text { \% terhadap konsentrasi } \\
\text { sampel b/v) }\end{array}$ & Larutan Stock D (ml) \\
\hline SL-1 & 50 & 2 \\
SL-2 & 75 & 3 \\
SL-3 & 100 & 4 \\
SL-4 & 125 & 5 \\
SL-5 & 150 & 6 \\
\hline
\end{tabular}


a. Parameter Spesifisitas

Pengujian spesifisitas sama dengan pengujian akurasi, presisi (kedapatulangan metode) dan rentang tetapi tanpa penambahan larutan stock dan hanya menggunakan matriks tablet.

\section{b. Parameter Ketegaran}

Sampel SK 3-1, SK 3-2, dan SK 33 yang digunakan untuk pengujian parameter akurasi, presisi (kedapatulangan metode), dan rentang disimpan pada suhu $15{ }^{\circ} \mathrm{C}$ selama 24 jam. Kemudian diukur absorbansi sampel pada $\lambda$ maksimum 550 $\mathrm{nm}$ dengan spektrofotometer UV-VIS menggunakan larutan standar yang baru yang disiapkan seperti pada penyiapan larutan standar untuk sampel, dan digunakan $\mathrm{HCl}$ 0,1 $\mathrm{N}$ sebagai blanko.

5. Penyiapan Larutan Stock
Cyanocobalamin

a. Larutan Stock A

Cyanocobalamin yang telah dikeringkan selama \pm 2 jam pada suhu $105^{\circ} \mathrm{C}$ ditimbang $\pm 110 \mathrm{mg}$, dimasukkan ke dalam labu ukur cokelat $100 \mathrm{ml}$, dilarutkan dan diencerkan dengan $\mathrm{HCl} 0,1 \mathrm{~N}$ hingga tanda batas, kemudian dikocok hingga homogen.

\section{b. Larutan Stock B}

Cyanocobalamin yang telah dikeringkan selama \pm 2 jam pada suhu $105^{\circ} \mathrm{C}$ ditimbang $\pm 200 \mathrm{mg}$, dimasukkan ke dalam labu ukur cokelat $100 \mathrm{ml}$, dilarutkan dan diencerkan dengan $\mathrm{HCl} 0,1 \mathrm{~N}$ hingga tanda batas, kemudian dikocok hingga homogen.

\section{c. Larutan Stock C}

Cyanocobalamin yang telah dikeringkan selama \pm 2 jam pada suhu $105^{\circ} \mathrm{C}$ ditimbang $\pm 90 \mathrm{mg}$, dimasukkan ke dalam labu ukur cokelat $100 \mathrm{ml}$, dilarutkan dan diencerkan dengan $\mathrm{HCl} 0,1 \mathrm{~N}$ hingga tanda batas, kemudian dikocok hingga homogen.

\section{d. Larutan Stock D}

Cyanocobalamin yang telah dikeringkan selama \pm 2 jam pada suhu $105^{\circ} \mathrm{C}$ ditimbang $\pm 150 \mathrm{mg}$, dimasukkan ke dalam labu ukur cokelat $100 \mathrm{ml}$, dilarutkan dan diencerkan dengan $\mathrm{HCl} 0,1 \mathrm{~N}$ hingga tanda batas, kemudian dikocok hingga homogen.

\section{HASIL DAN PEMBAHASAN}

\section{A. Linieritas}

Menurut International Conference Harmonization Guidelines (1994), linieritas merupakan kemampuan metode analisis yang memberikan respon secara langsung terhadap konsentrasi analit dalam contoh. Linieritas atau kecenderungan korelasi antara dua variable biasanya dinyatakan dalam koefisien korelasi (r). Hasil analisis didapatkan harga $r=0,999$ dimana sesuai dengan persyaratan penerimaan $\mathrm{r}$ dalam sediaan obat yaitu > 0,98 . Hal ini menandakan sampel yang dianalisis stabil dan homogen. Hasil linieritas cyanocobalamin dapat dilihat pada Tabel 3 dan kurva hasil uji linieritas cyanocobalamin dapat dilihat pada Gambar 1.

\section{B. Presisi}

Menurut Harmita (2004), pengujian presisi kedapatulangan metode dilakukan sebanyak 15 kali pengukuran kadar. Memenuhi persyaratan penerimaan jika simpangan baku relatif (SBR) $\leq 2 \%$. Berdasarkan uji presisi untuk kedapatulangan metode diperoleh hasil SBR yang memenuhi persyaratan yaitu $80 \%=0,30 \%, 90 \%=0,38 \%, 100 \%=$ $0,33 \%, 110 \%=0,26 \%$ dan $120 \%=0,25 \%$. Hasil presisi untuk kedapatulangan metode cyanocobalamin dapat dilihat pada Tabel 4 dan diagram presisi untuk kedapatulangan metode cyanocobalamin dapat dilihat pada Gambar 2. 
C. Presisi Antara

Menurut International Conference Harmonization Guidelines (1994), pengujian presisi antara dilakukan tiga kali ulangan oleh orang yang berbeda dan pada waktu yang berbeda pula. Memenuhi persyaratan penerimaan jika $\mathrm{SBR} \leq 2 \%$.
Berdasarkan uji presisi antara yang dilakukan terhadap cyanocobalamin diperoleh SBR yang kurang dari 2 yaitu $0,00 \%$ hasil ini memenuhi persyaratan. Hasil presisi antara cyanocobalamin dapat dilihat pada Tabel 5 dan diagram presisi antara cyanocobalamin dapat dilihat pada Gambar 3.

Tabel 3. Hasil Linieritas Cyanocobalamin

\begin{tabular}{lccccc}
\hline No. & $\begin{array}{c}\text { Konsentrasi } \\
\text { Teoritis } \\
(\% \text { terhadap } \\
\text { konsentrasi } \\
\text { sampel b/v) }\end{array}$ & $\begin{array}{c}\text { Bobot } \\
\text { Sampel } \\
\text { Aktual } \\
(\mathrm{mg})\end{array}$ & $\begin{array}{c}\text { Absorban } \\
\text { Sampel Rata }- \\
\text { Rata }\end{array}$ & $\begin{array}{c}\text { Konsentrasi } \\
\text { Terkoreksi } \\
\text { \% terhadap } \\
\text { konsentrasi } \\
\text { sampel b/v })\end{array}$ & $\mathrm{R}$ \\
\hline 1. & 50 & & 0,1855 & 50,05 & \\
2. & 75 & & 0,272 & 75,08 & \\
3. & 100 & 0,07508 & 0,362 & 100,11 & 0,999 \\
4. & 125 & & 0,449 & 125,13 & \\
5. & 150 & & 0,544 & 150,16 & \\
\hline
\end{tabular}

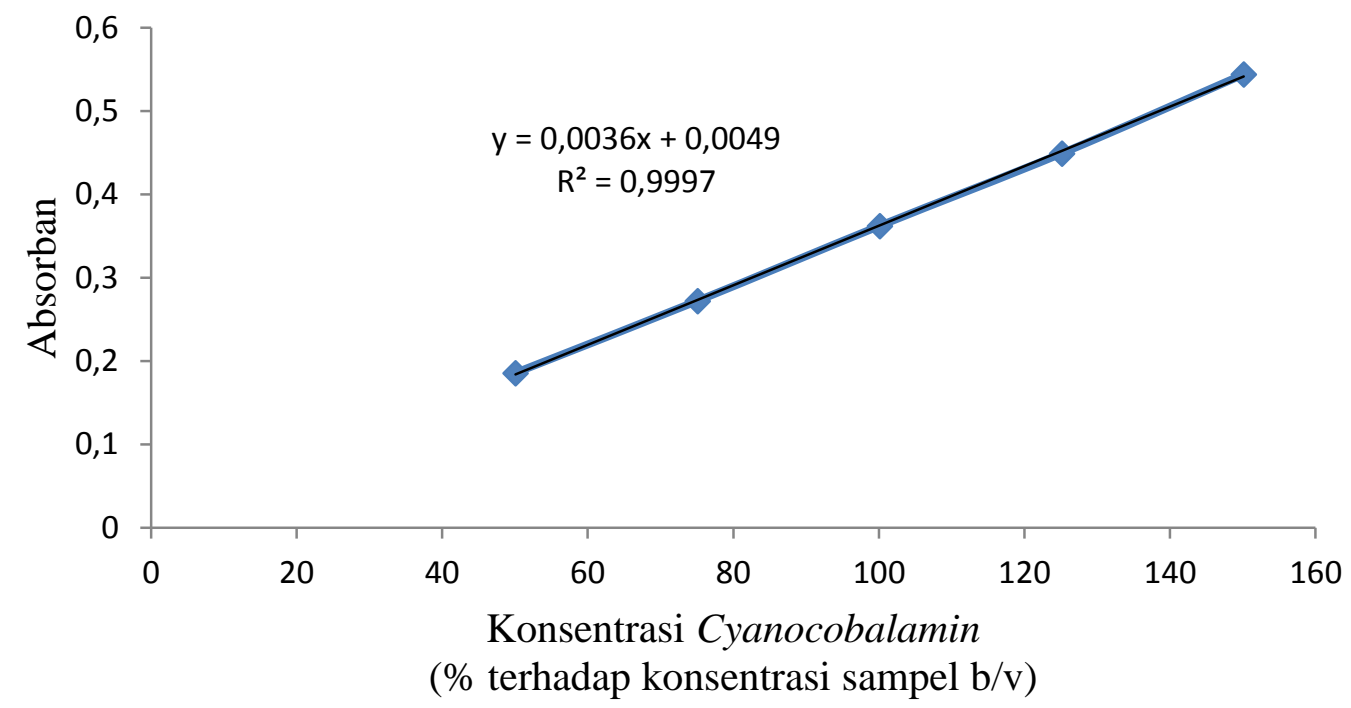

Gambar 1. Kurva Linieritas Cyanocobalamin 
Tabel 4. Hasil Presisi untuk Kedapatulangan Metode Cyanocobalamin

\begin{tabular}{cccccccc}
\hline & $\begin{array}{c}\text { Konsentrasi } \\
\text { Teoritis }(\% \\
\text { Kode }\end{array}$ & $\begin{array}{c}\text { Bobot } \\
\text { Sampel } \\
\text { kampenap } \\
\text { konsentrasi } \\
\text { sampel b/v) }\end{array}$ & $\begin{array}{c}\text { Absorban } \\
\text { Sampel } \\
\text { Sata }- \\
\text { Rata }\end{array}$ & $\begin{array}{c}\text { Bobot } \\
\text { Standar } \\
\text { Aktual } \\
(\mathrm{mg})\end{array}$ & $\begin{array}{c}\text { Absorban } \\
\text { Standar } \\
\text { Rata }- \\
\text { Rata }\end{array}$ & $\begin{array}{c}\text { Konsentrasi } \\
\text { Aktual } \% \\
\text { terhadap } \\
\text { konsentrasi } \\
\text { sampel b/v) }\end{array}$ & $\begin{array}{c}\text { SBR } \\
(\%)\end{array}$ \\
\hline $1-1$ & 80 & & 0,2855 & & & 79,17 & \\
$1-2$ & 80 & 200,16 & 0,284 & 50,00 & 0,361 & 78,76 & 0,30 \\
$1-3$ & 80 & & 0,2855 & & & 79,17 & \\
$2-1$ & 90 & & 0,305 & & & 89,36 & \\
$2-2$ & 90 & 90,24 & 0,305 & 50,22 & 0,34375 & 89,36 & 0,38 \\
$2-3$ & 90 & & 0,307 & & & 89,95 & \\
$3-1$ & 100 & & 0,349 & & & 98,85 & \\
$3-2$ & 100 & 200,01 & 0,347 & 50,03 & 0,35225 & 98,28 & 0,33 \\
$3-3$ & 100 & & 0,349 & & & 98,85 & \\
$4-1$ & 110 & & 0,385 & & & 108,56 & \\
$4-2$ & 110 & 110,09 & 0,387 & 50,02 & 0,35375 & 109,12 & 0,26 \\
$4-3$ & 110 & & 0,386 & & & 108,84 & \\
$5-1$ & 120 & & 0,4225 & & & 118,17 & \\
$5-2$ & 120 & 200,24 & 0,424 & 50,06 & 0,356 & 118,59 & 0,25 \\
$5-3$ & 120 & & 0,422 & & & 118,03 & \\
\hline
\end{tabular}

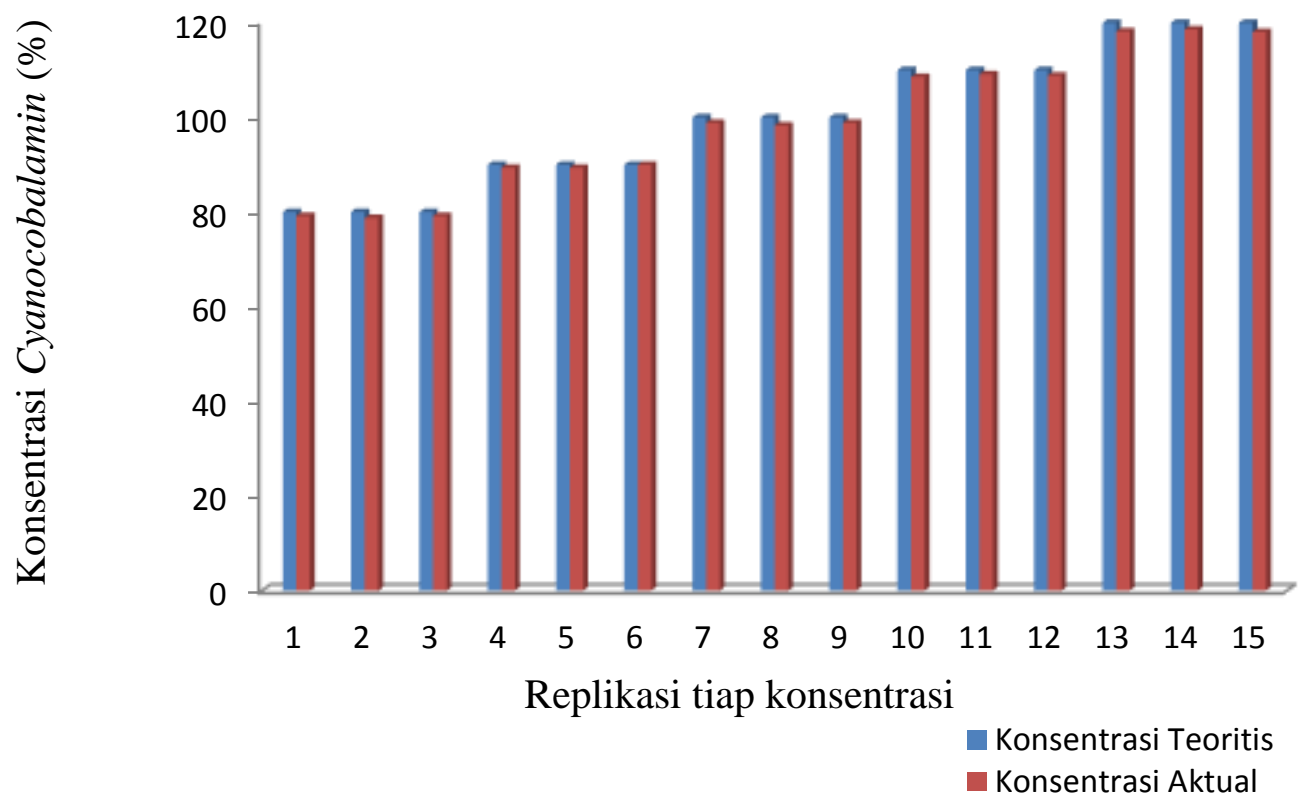

Gambar 2. Diagram Hasil Uji Presisi untuk Kedapatulangan Metode Cyanocobalamin 
Tabel 5. Hasil Presisi Antara Cyanocobalamin

\begin{tabular}{cccccccc}
\hline Kode & $\begin{array}{c}\text { Konsentrasi } \\
\text { Teoritis }(\% \\
\text { terhadap } \\
\text { Sonsentrasi } \\
\text { Sampel b/v) }\end{array}$ & $\begin{array}{c}\text { Bobot } \\
\text { Sampel } \\
\text { Aktual } \\
(\mathrm{mg})\end{array}$ & $\begin{array}{c}\text { Absorban } \\
\text { Sampel } \\
\text { Rata }- \\
\text { Rata }\end{array}$ & $\begin{array}{c}\text { Bobot } \\
\text { Standar } \\
\text { Aktual } \\
(\mathrm{mg})\end{array}$ & $\begin{array}{c}\text { Absorban } \\
\text { Standar } \\
\text { Rata }- \\
\text { Rata }\end{array}$ & $\begin{array}{c}\text { Konsentrasi } \\
\text { Aktual }(\% \\
\text { terhadap } \\
\text { konsentrasi } \\
\text { sampel b/v) }\end{array}$ & $\begin{array}{c}\text { SBR } \\
(\%)\end{array}$ \\
\hline $3-4$ & 100 & & 0,348 & & & 99,16 & \\
$3-5$ & 100 & 200,95 & 0,348 & 50,50 & 0,3525 & 99,16 & 0,00 \\
$3-6$ & 100 & & 0,348 & & & 99,16 & \\
\hline
\end{tabular}

A. Akurasi

Menurut Firdaus (2004), akurasi merupakan ukuran ketepatan hasil analisis dengan kadar analit yang sebenarnya. Akurasi sering dinyatakan sebagai perolehan kembali atau recovery. Uji akurasi menunjukkan ketepatan antara nilai yang dihasilkan pada saat penetapan kadar cyanocobalamin dengan nilai sebenarnya. Hasil perolehan kembali (recovery) yang didapat dari hasil analisis adalah 98,12\% 99,44\% dengan demikian akurasi hasil analisis yang didapatkan telah memenuhi persyaratan yaitu 98\% - 102\%. Hasil akurasi cyanocobalamin dapat dilihat pada Tabel 6 dan diagram akurasi cyanocobalamin dapat dilihat pada Gambar 4.

\section{B. Ketegaran}

Menurut Harmita (2004), ketegaran merupakan kapasitas suatu prosedur analitik untuk tidak terpengaruh oleh variasi kecil dalam parameter metode yang akan memberikan indikasi kehandalan prosedur analitik selama aplikasi yang normal. Parameter yang diuji pada validasi metode ketegaran bisa berupa pengaruh waktu penyimpanan. Memenuhi persyaratan penerimaan jika SBR $\leq 2 \%$ dan $\%$ recovery $98 \%-102 \%$. Berdasarkan uji ketegaran yang dilakukan pada konsentrasi $100 \%$ sebanyak 3 kali diperoleh SBR yang kurang dari $2 \%$ yaitu $0,00 \%$ dan hasil perolehan kembali (recovery) yaitu $98,24 \%$ dengan demikian hasil analisis yang didapatkan telah memenuhi persyaratan SBR dan recovery. Hal ini menandakan kestabilan sampel yang telah didiamkan selama 24 jam di dalam lemari pendingin bersuhu sekitar $15^{\circ} \mathrm{C}$. Hasil ketegaran cyanocobalamin dapat dilihat pada Tabel 7 dan diagram ketegaran cyanocobalamin dapat dilihat pada Gambar 5.

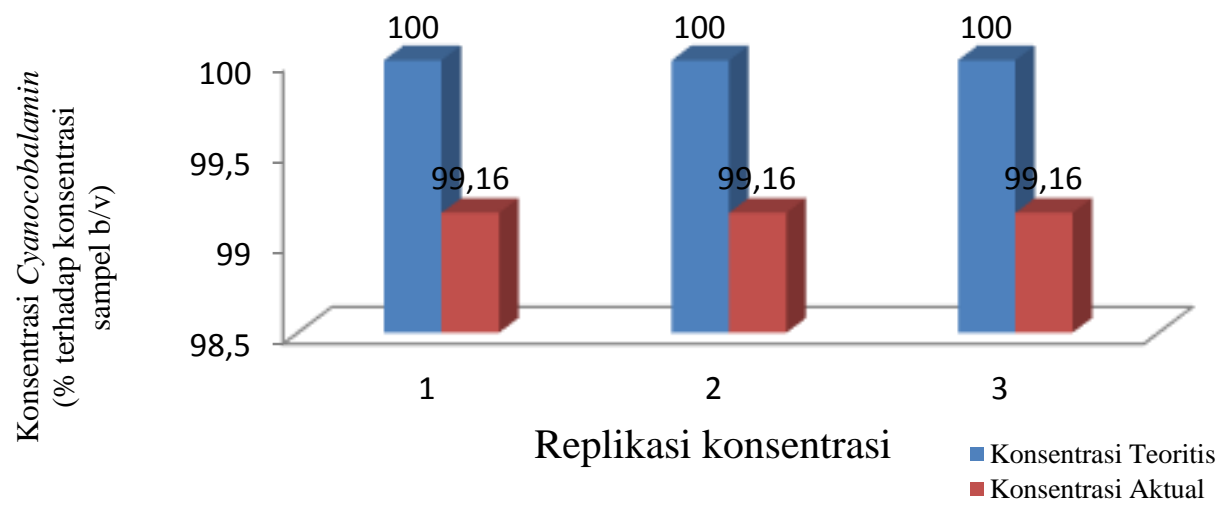

Gambar 3. Diagram Hasil Uji Presisi Antara Cyanocobalamin 
Tabel 6. Hasil Akurasi Cyanocobalamin

\begin{tabular}{|c|c|c|c|c|c|c|c|}
\hline $\begin{array}{c}\text { Kode } \\
\text { Sampel }\end{array}$ & $\begin{array}{c}\text { Konsen } \\
\text { trasi } \\
\text { Teoritis } \\
(\% \\
\text { terhadap } \\
\text { konsen } \\
\text { trasi } \\
\text { sampel } \\
\text { b/v) } \\
\end{array}$ & $\begin{array}{c}\text { Bobot } \\
\text { Sampel } \\
\text { Aktual } \\
(\mathrm{mg})\end{array}$ & $\begin{array}{c}\text { Absor } \\
\text { ban } \\
\text { Sampel } \\
\text { Rata - } \\
\text { Rata }\end{array}$ & $\begin{array}{c}\text { Bobot } \\
\text { Stan } \\
\text { dar } \\
\text { Aktua } \\
1(\mathrm{mg})\end{array}$ & $\begin{array}{l}\text { Absor } \\
\text { ban } \\
\text { Standar } \\
\text { Rata - } \\
\text { Rata }\end{array}$ & $\begin{array}{c}\text { Konsen } \\
\text { trasi } \\
\text { Aktual } \\
(\% \\
\text { terhadap } \\
\text { konsen } \\
\text { trasi } \\
\text { sampel } \\
\text { b/v) } \\
\end{array}$ & $\begin{array}{l}\text { Reco } \\
\text { very } \\
(\%)\end{array}$ \\
\hline $1-1$ & 80 & & 0,2855 & & & 79,17 & 98,92 \\
\hline $1-2$ & 80 & 200,16 & 0,284 & 50,00 & 0,361 & 78,76 & 98,41 \\
\hline $1-3$ & 80 & & 0,2855 & & & 79,17 & 98,92 \\
\hline $2-1$ & 90 & & 0,305 & & & 89,36 & 98,79 \\
\hline $2-2$ & 90 & 90,24 & 0,305 & 50,22 & 0,34375 & 89,36 & 98,79 \\
\hline $2-3$ & 90 & & 0,307 & & & 89,95 & 99,44 \\
\hline $3-1$ & 100 & & 0,349 & & & 98,85 & 98,85 \\
\hline $3-2$ & 100 & 200,01 & 0,347 & 50,03 & 0,35225 & 98,28 & 98,28 \\
\hline $3-3$ & 100 & & 0,349 & & & 98,85 & 98,85 \\
\hline $4-1$ & 110 & & 0,385 & & & 108,56 & 98,42 \\
\hline $4-2$ & 110 & 110,09 & 0,387 & 50,02 & 0,35375 & 109,12 & 98,92 \\
\hline 4-3 & 110 & & 0,386 & & & 108,84 & 98,67 \\
\hline $5-1$ & 120 & & 0,4225 & & & 118,17 & 98,24 \\
\hline $5-2$ & 120 & 200,24 & 0,424 & 50,06 & 0,356 & 118,59 & 98,59 \\
\hline $5-3$ & 120 & & 0,422 & & & 118,03 & 98,12 \\
\hline
\end{tabular}

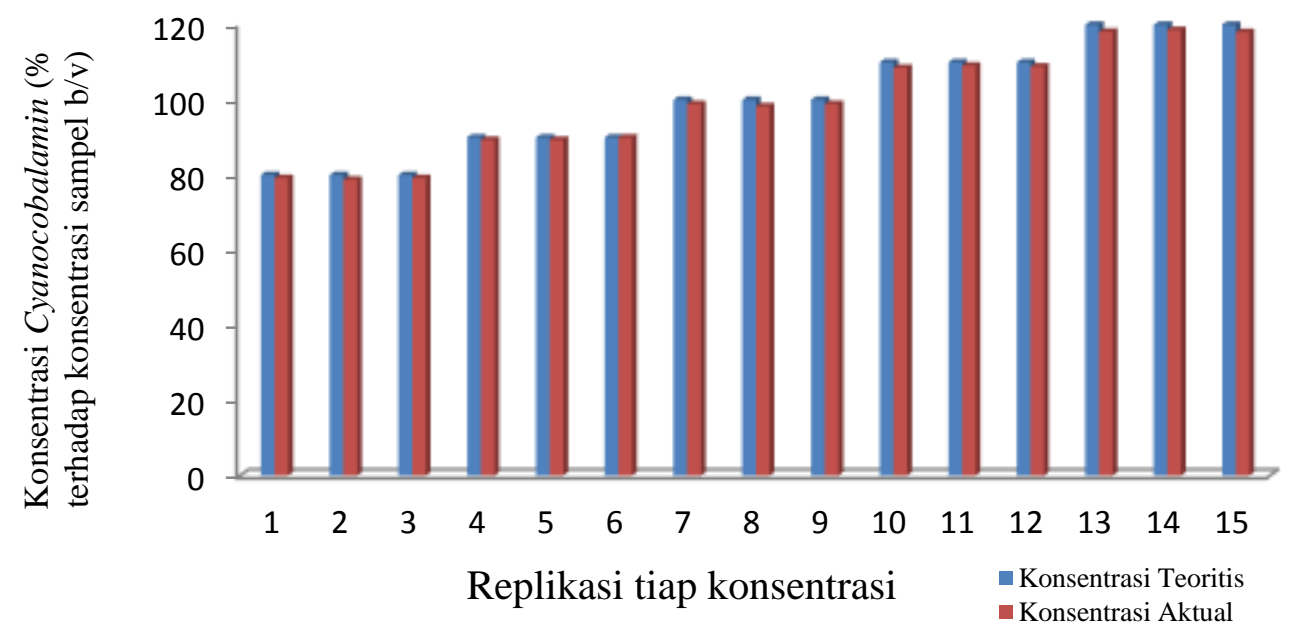

Gambar 4. Diagram Hasil Uji Akurasi Cyanocobalamin 
Tabel 7. Hasil Ketegaran Cyanocobalamin

\begin{tabular}{|c|c|c|c|c|c|c|c|c|}
\hline $\begin{array}{c}\text { Kode } \\
\text { Sam } \\
\text { pel }\end{array}$ & $\begin{array}{c}\text { Konsen } \\
\text { trasi } \\
\text { Teoritis } \\
(\% \\
\text { terhadap } \\
\text { konsen } \\
\text { trasi } \\
\text { sampel } \\
\text { b/v) } \\
\end{array}$ & $\begin{array}{c}\text { Bobot } \\
\text { Sampel } \\
\text { Aktual } \\
(\mathrm{mg})\end{array}$ & $\begin{array}{l}\text { Absorb } \\
\text { an } \\
\text { Sampel } \\
\text { Rata - } \\
\text { Rata }\end{array}$ & $\begin{array}{c}\text { Bobot } \\
\text { Standar } \\
\text { Aktual } \\
(\mathrm{mg})\end{array}$ & $\begin{array}{l}\text { Absorb } \\
\text { an } \\
\text { Standar } \\
\text { Rata - } \\
\text { Rata }\end{array}$ & $\begin{array}{c}\text { Konsen } \\
\text { trasi } \\
\text { Aktual } \\
(\% \\
\text { terhadap } \\
\text { konsentra } \\
\text { si sampel } \\
\text { b/v) }\end{array}$ & $\begin{array}{c}\text { SBR } \\
(\%)\end{array}$ & $\begin{array}{l}\text { Recove } \\
\text { ry }(\%)\end{array}$ \\
\hline $3-1$ & 100 & & 0,354 & & & 98,24 & & 98,24 \\
\hline $3-2$ & 100 & 200,01 & 0,354 & 50,00 & 0,361 & 98,24 & 0,00 & 98,24 \\
\hline $3-3$ & 100 & & 0,354 & & & 98,24 & & 98,24 \\
\hline
\end{tabular}

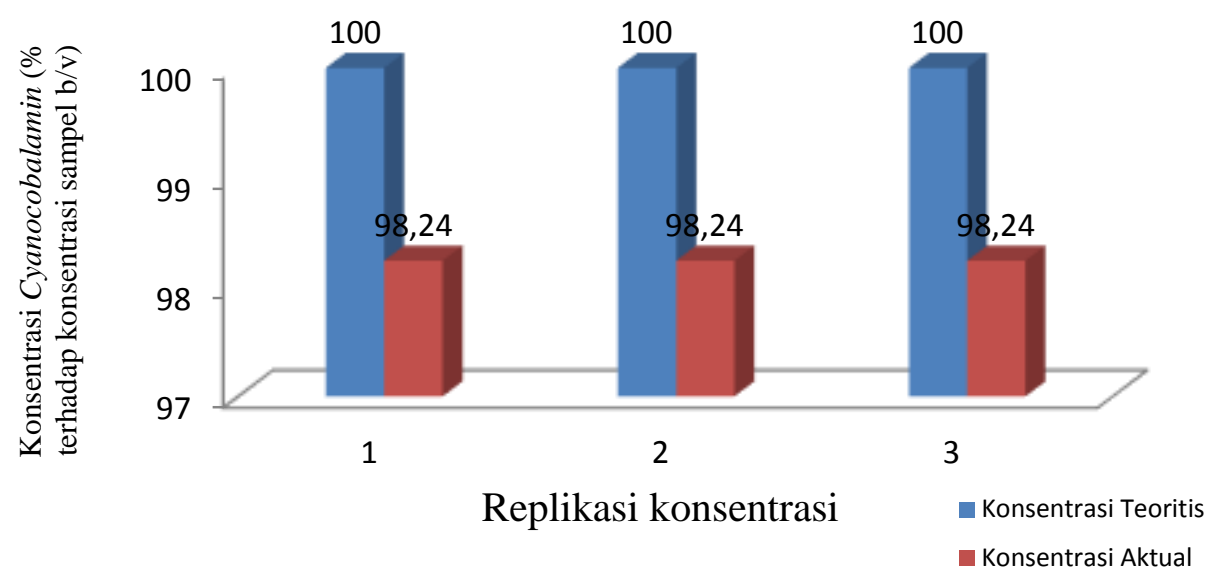

Gambar 5. Diagram Hasil Uji Ketegaran Cyanocobalamin

F. Ketegaran

Dilakukan juga pengukuran puncak untuk larutan matriks tablet dengan spektrofotometer visibel double beam yang bertujuan untuk menunjukkan bahwa pada panjang gelombang maksimum $550 \mathrm{~nm}$ dari sampel sediaan tablet cyanocobalamin matriks tablet tidak memberikan serapan yang berarti.

\section{G. Rentang}

Berdasarkan hasil analisis dari parameter presisi dan akurasi pada rentang konsentrasi yang dipersyaratkan, dimana
$\%$ recovery dan simpangan baku relatif memenuhi kriteria penerimaan, maka dapat disimpulkan untuk parameter rentang pada validasi metode penetapan kadar cyanocobalamin ini juga memenuhi kriteria penerimaan yang disyaratkan.

\section{KESIMPULAN}

1. Metode penetapan kadar cyanocobalamin dinyatakan valid.

2. Hasil parameter ketegaran didapatkan hasil yang stabil untuk penyimpanan larutan sampel selama 24 jam pada lemari pendingin bersuhu $15^{\circ} \mathrm{C}$. 


\section{DAFTAR PUSTAKA}

Departemen Kesehatan Republik Indonesia. 1995. Farmacope Indonesia. Edisi IV.

Departemen Kesehatan Republik Indonesia. Jakarta.

Firdaus, D. R. 2004. Validasi Metode Analisis C-14 Menggunakan Teknologi Preparasi Tangkapan Gas $\mathrm{CO}_{2}$ Dalam Sistem Loop. Skripsi. Universitas Nusa Bangsa. Bogor.

Harmita. 2004. Validasi Metode Analisis. Majalah Ilmu Kefarmasian.
Volume I, Nomor 3. Departemen Farmasi FMIPA Universitas Indonesia. Jakarta.

International Conference Harmonization Guidelines. 1994. Validation of Analytical Methods : Definitions and Terminology. International Conference Harmonization Guidelines.

Nalco Chemical Company. 2006. Resin Rinse, Productivity Management for Ion Exchange. USA.

The Committee on JP. 2006. The Japanese Pharmacopoeia. Edisi XV. The Committee on JP. Jepang. 